[This paper appeared in Philosophical Studies 138.2 (March 2008): 151-160. The official version is available to subscribers at

http://www.Springerlink.com/content/t1706160j4j31107/fulltext.pdf.]

\title{
Modal fictionalism and possible-worlds discourse
}

David Liggins

\begin{abstract}
The Brock-Rosen problem has been one of the most thoroughly discussed objections to the modal fictionalism bruited in Gideon Rosen's 'Modal Fictionalism'. But there is a more fundamental problem with modal fictionalism, at least as it is normally explained: the position does not resolve the tension that motivated it. I argue that if we pay attention to a neglected aspect of modal fictionalism, we will see how to resolve this tension - and we will also find a persuasive reply to the Brock-Rosen objection. Finally, I discuss an alternative reading of Rosen, and argue that this position is also able to fend off the Brock-Rosen objection.
\end{abstract}

1. The Brock-Rosen problem has been one of the most thoroughly discussed objections to the modal fictionalism bruited in Rosen 1990. But there is a more fundamental problem with modal fictionalism, at least as it is normally explained: the position does not resolve the tension that motivated it. I argue that if we pay attention to a neglected aspect of modal fictionalism, we will see how to resolve this tension - and we will also find a persuasive reply to the Brock-Rosen objection. Finally, I discuss an alternative reading of Rosen, and argue that this position is also able to fend off the Brock-Rosen objection.

2. Talk about possible worlds improves the clarity of our philosophical discussions through enabling us to articulate modal claims more clearly. Indeed, possible-worlds talk is so useful that we would be loath to give it up. But there is a dilemma in prospect. Many of the things we say when we are speaking of possible worlds appear to imply the existence of worlds that are not the actual world (I'll call these 'merely possible' worlds). For example, suppose that I claim 
that there could have been zombies - people who share our physical properties but lack phenomenal consciousness. I will want to say

$\mathrm{Z} \quad$ There is a world at which there are zombies.

But since there are no zombies in this world (let me assume), $\mathrm{Z}$ looks as though it implies the existence of a merely possible world.

Modal realists are happy to believe that there are merely possible worlds as well as the actual world. I'll call the proposition that they believe 'Plurality'. Belief in Plurality is distinctive of modal realism. It seems that if I believe $\mathrm{Z}$ to be true, I have to commit myself to Plurality. However, many philosophers are unwilling to believe Plurality. Even David Lewis, the staunchest defender of a version of Plurality, admitted that his view clashes violently with our pre-theoretical beliefs about what exists (Lewis 1986: 133). ${ }^{1}$ So there is an apparent tension between engaging in possible-worlds talk and refusing to assert Plurality. We are caught in a dilemma: we must either assert Plurality or stop taking part in possible-worlds discourse.

3. Gideon Rosen begins his 1990 by outlining just this tension. He goes on to discuss the prospects for a way of resolving it, called modal fictionalism. This doctrine hinges on the use of a 'story prefix': according to the hypothesis of the plurality of worlds (or Acc to PW for short), where the hypothesis in question is David Lewis's modal realism. The crucial thing about this prefix is that it is non-factive: that something is true according to the hypothesis of the plurality of worlds does not entail that it $i s$ true. For instance, it may well be true that, although $\mathrm{Z}$ is false, the sentence

Z+ According to the hypothesis of the plurality of worlds, there is a world at which there are zombies.

is true. 
One benefit gained by those who engage in possible worlds talk is that they can provide a semantics for sentences of English which include the modal expressions 'necessarily', 'possibly', 'could have', and the like. Call these modal sentences. (Note that sentences about worlds - Z, for instance - do not typically count as modal.) Modal realists offer a possible worlds semantics for these sentences, which amounts to asserting all instances of the schema

$P W S \quad p$ iff $p^{*}$

where $p$ is any modal sentence, and $p^{*}$ a translation of it into worlds talk. For instance,

B There could have been a blue swan

is translated as

B* There is a world at which there is a blue swan.

Modal fictionalism is usually introduced in the following manner. In place of $P W S$, the modal fictionalist offers a new semantics. According to the modal fictionalist, B does not mean $\mathrm{B}^{*}$, but instead means

$\mathrm{B}+$ According to the hypothesis of the plurality of worlds, there is a world at which there is a blue swan.

More generally, the modal fictionalist replaces $P W S$ with $M F$ :

MF $\quad p$ iff Acc to PW, $p^{*}$

where, as before, $p$ ranges over modal sentences. Modal fictionalists assert all instances of this schema. 
Asserting all instances of $M F$ is not sufficient for modal fictionalism, since $M F$ does not make it clear that modal fictionalism offers an account of the truth-conditions of modal sentences, rather than an account of the truth-conditions of sentences that are instances of the right-hand side of the schema. To put the point another way, $M F$ (as it stands) is quite compatible with the doctrine that sentences like 'According to the hypothesis of the plurality of worlds, $p^{*}$ ' do not wear their truth-conditions on their sleeves, and that the truth-conditions of each sentence of this sort are more perspicuously represented by the modal sentence of which $p^{*}$ is the translation. (For example, $\mathrm{B}^{*}$ would be more perspicuously represented by B.) But that is not modal fictionalism, for modal fictionalism claims that modal sentences express propositions that are more perspicuously expressed b y sentences about the plurality of worlds hypothesis - not the other way round. To capture this asymmetry, we need to stipulate that instances of $M F$ are to be understood so that the right-hand side takes semantic priority, in the way I have just explained. ${ }^{2}$

4. There is something very puzzling about the idea that $M F$ resolves the tension with which I began. The dilemma concerned possible-worlds sentences: how can we go on using them without committing ourselves to Plurality? But $M F$ says nothing about the vast majority of possible-worlds sentences, confining itself to an account of modal sentences. (Some modal sentences are also possible-worlds sentences: witness 'Necessarily, there is a plurality of worlds'. But most possible-worlds sentences contain no modal language, in the sense introduced in the previous section.) The reader is therefore left in the dark about how asserting all instances of $M F$ gives the fictionalist the right to go on using possible worlds sentences like Z. According to modal fictionalism, 'you can have all the benefits of talking about possible worlds without the ontological costs' (Rosen 1990: 330). But how can modal fictionalism deliver this without giving an account of possible-worlds discourse?

There are two obvious strategies for resolving the initial dilemma. One is to maintain that sentences like $\mathrm{Z}$ are free of commitment to merely possible worlds: whilst they may appear to entail Plurality, they do not genuinely do so. If this is the case, then we may endorse them freely with no immediate threat of commitment to Plurality. The other strategy maintains 
that sentences like $\mathrm{Z}$ do indeed entail Plurality, so that anyone who endorses them must believe Plurality to be true; but that it is permissible to go on uttering these sentences without believing them.

Rosen says several things that suggest the first of these strategies. (In §6, I will explore a reading of Rosen which sees him as taking the second strategy.) For instance, he introduces a character called Ed, who is feeling the force of the dilemma. Rosen writes:

[A] theorist who rejects ersatzism ... but at the same time finds the realist's metaphysical picture impossible to accept ... has good reason to look into Ed's remaining option - to interpret his apparent quantification over possible worlds as an innocent façon de parler, involving no commitment to possible worlds of any sort. (Rosen 1990: 329-330)

Rosen labels this approach 'deflationist', and he goes on to explain modal fictionalism. It seems that Rosen intends to offer us an interpretation of possible-worlds discourse which explains why modal fictionalists can engage in it without commitment to Plurality. (It should be clear that $M F$ offers us no such thing.)

Elsewhere, Rosen says:

The fictionalist about possible worlds ... interpret[s] his own apparent quantification over worlds as quantification within the scope of a story prefix. ... [T] claims about possible worlds will always be elliptical for claims about the content of a story ... (Rosen 1993a: 71)

This suggests that the definition of modal fictionalism given above is inadequate: we should supplement it with an interpretation of possible-worlds sentences as they are used by fictionalists. This interpretation is given by all instances of the following schema: 
where $p$ is any non-modal possible worlds sentence. Call the resulting position reinforced modal fictionalism ('RM fictionalism', for short). RM fictionalism offers a resolution of the initial dilemma, since RM fictionalists can explain why it is legitimate to go on uttering sentences like $\mathrm{Z}$ without believing in a plurality of worlds. According to RM fictionalism, their utterances simply express claims about the content of Lewis's theory: claims like Z+. And so their assertions do not commit them to beliefs about a plurality of worlds - merely to beliefs about a philosophical hypothesis.

This way of resolving the tension is not new: it is already suggested in Rosen 1990. But it has been largely neglected by the ensuing debate. Modal fictionalism is frequently expounded by simply presenting the schema $M F$. For instance, Harold Noonan writes:

Gideon Rosen puts forward an account of modal discourse which suggests how one can translate such discourse into possible worlds discourse without any untoward ontological commitments. ... [Rosen's] suggestion is the following. Let P be any modal sentence and $\mathrm{P}_{\mathrm{L}}$ its translation into Lewisian counterpart theory. Then, Rosen suggests, the correct translation of $\mathrm{P}$ into possible world discourse is not $\mathrm{P}_{\mathrm{L}}$ but rather 'According to the Lewisian hypothesis of a plurality of worlds, $\mathrm{P}_{\mathrm{L}}{ }^{\prime} \ldots$... (Noonan 1994: 133)

There is no mention here of possible-worlds sentences or how Rosen proposes to treat them. The same deficiency can be found in the expositions of modal fictionalism offered in Nolan and O'Leary Hawthorne 1996, Baldwin 1998, Chihara 1998, Kim 2002, and Dever 2003. And even philosophers who mention that modal fictionalism offers an interpretation of possible-worlds discourse then go on to ignore this aspect of the view, treating modal fictionalism as though it were confined to $M F$ (thus, for example, Brock 1993).

I have argued that we must take this neglected aspect of modal fictionalism seriously if we are to resolve the tension concerning possible-worlds discourse which motivated the position in the first place. I will now argue that if we do so, we will find that fictionalism can 
repel one of the most troublesome objections that has been launched at it: namely, the Brock-Rosen objection.

5. Rosen does not endorse the modal fictionalism he put forward (see Chihara 1998: 169) indeed, he was one of its earliest critics. Rosen (1993a) and Stuart Brock (1993) independently hit upon an objection to modal fictionalism which purports to show that the modal fictionalist $i s$ committed to Plurality after all.

The objection can be stated as follows. Modal fictionalists must believe that the following argument is sound:

(1) Necessarily, there is a plurality of worlds iff Acc to PW, at all worlds, there is a plurality of worlds. (Instance of $M F$ )

(2) Acc to PW, at all worlds, there is a plurality of worlds. (Plausible claim about Lewis's theory)

(3) Necessarily, there is a plurality of worlds. (1, 2 modus ponens)

(4) There is a plurality of worlds. (4 standard modal logic)

But if modal fictionalists believe that this is sound, then they must endorse its conclusion. And so they are forced to take on belief in a plurality of words - exactly what modal fictionalism was intended to avoid.

Brock and Rosen have now accepted the response to their objection proposed by Noonan (1994) (see Rosen 1995: 68 and Brock 2002: 20 n. 9). Noonan recommends that the fictionalist exploit the method for translating modal claims into the language of possible worlds proposed in Lewis 1968, according to which (2) is false. I lack the space to assail Noonan's approach; but see Divers 1999a, Divers and Hagen 2006, and Kim 2002 for reasons why modal fictionalists should reject the Lewis 1968 translation scheme. ${ }^{3}$

To understand how RM fictionalists can see off the objection, consider a related objection to their position, running as follows: 
RM fictionalists are committed to Plurality, because they believe that there is a world at which there is a blue swan! After all, they must believe that this argument is sound:

There is a world at which there are blue swans iff Acc to PW, there is a world at which there are blue swans. (Instance of $M F 2$ )

Acc to PW, there is a world at which there are blue swans. (Plausible claim about Lewis's theory)

There is a world at which there are blue swans. (Modus ponens)

Since there are no blue swans in the actual world, the conclusion of this argument commits RM fictionalists to the existence of a merely possible world. So they are Pluralists in disguise.

This objection fails. According to RM fictionalism, the conclusion of the argument expresses a truth, but one which is perfectly compatible with the denial of Plurality. It is natural to think that the proposition expressed by 'Acc to PW, there is a world at which there are blue swans' is both true and ontologically innocent. RM fictionalists contend that, in their mouths, the sentence 'There is a world at which there are blue swans' expresses this proposition - rather than (as we might have expected) a controversial ontological proposition entailing Plurality.

RM fictionalists can respond to the Brock-Rosen objection in just the same way. They should (i) concede the soundness of the argument mentioned in the statement of the objection, and thus (ii) concede that the conclusion of the argument ('There is a plurality of worlds') expresses a truth; but at the same time (iii) deny that this truth entails Plurality. For RM fictionalists, 'There is a plurality of worlds' expresses the proposition that is more transparently expressed by the sentence 'Acc to PW, at all worlds, there is a plurality of worlds'. (So MF2 says.) RM fictionalists should claim that this proposition can obtain even if there are 
no merely possible worlds. This is a highly plausible claim to make: surely Lewis's theory can incorporate Plurality whether or not Plurality is true.

Simplicity aside, what merits does this response to the Brock-Rosen objection have? Its principal advantage is that it treats the Brock-Rosen objection in the same way as the blue swan argument, which seems desirable. Given that RM fictionalism has the resources to resist the blue swan objection, and that these can be deployed to fend off the Brock-Rosen objection too, it seems ad hoc to counter Brock-Rosen in any other way. There is no need to resort to tinkering with the details of how modal claims are to be interpreted, as Noonan does. The new response to Brock-Rosen is the natural one to make.,

6. As I have said, there are various remarks of Rosen's which suggest that modal fictionalists should adopt RM fictionalism in order to escape the initial dilemma. RM fictionalists escape it by maintaining that sentences like $\mathrm{Z}$ carry no commitment to merely possible worlds. In $\S 4$, I mentioned a second way round the dilemma: to maintain that sentences like $\mathrm{Z}$ do indeed entail Plurality, but that we may continue to use these sentences without believing them. In a paper on another topic (nominalism in mathematics), Rosen writes:

A theorist's commitments depend upon what he believes, not upon what he happens to utter. The method of ontological reduction by paraphrase works when it does by providing the theorist with a systematic account of how his utterances don't straightforwardly reflect his beliefs. Such reductions therefore function at the level of pragmatics rather than semantics, and involve no strong claims about the commitments of sentences or statements taken literally. (Rosen 1993b: 164, footnote omitted)

Rosen (1992: 184 fn. 26) says he thinks this the only coherent way to understand 'deflationism' about possible worlds. But, as we have seen, he characterises modal fictionalism as a version of deflationism. So this passage is evidence for the view that Rosen intended modal fictionalists to take the second way round the dilemma, rather than providing an interpretation of possible worlds talk that reveals that none of these sentences entails Plurality. On this view, Z entails 
Plurality, but modal fictionalists can utter it without having to believe Plurality provided they do not assert it. They can utter it to express a different belief - the belief that, according to the plurality of worlds hypothesis, there is a world at which there are zombies.

Let us call this version of modal fictionalism 'pragmatic modal fictionalism', or 'PM fictionalism' for short. I will not consider the question of whether Rosen meant to put forward RM fictionalism or PM fictionalism. Instead, I will now argue that the Brock-Rosen objection presents no threat to PM fictionalism, because PM fictionalists are not committed to (1).

A PM fictionalist who utters $\mathrm{Z}$ in the context of a philosophical debate (say, about the philosophy of mind) does not believe the proposition which she thinks it expresses. For she is aware that if she believed this proposition, she would be committed to believing Plurality. Rather, she believes the proposition expressed by the paraphrase Z+ ('According to the hypothesis of the plurality of worlds, there is a world at which there are zombies'). This is a proposition about Lewis's theory, and, as such, is innocent of commitment to Plurality.

The following is an instance of $M F$ :

(*) There is a world at which there are zombies iff according to the hypothesis of the plurality of worlds, there is a world at which there are zombies.

It is part of PM fictionalism to refrain from asserting this biconditional. PM fictionalists are happy to assert the right-hand side, which is just Z+. But if they asserted the biconditional, then they would also have to assert the left-hand side, which is $\mathrm{Z}$ - and it is part of PM fictionalism not to assert Z, or any kindred possible-worlds sentences.

As I have explained matters, fictionalists refuse to assert Plurality because they do not believe it. There is a stronger position in the vicinity: that of believing and asserting the negation of Plurality. PM fictionalists who adopt this stronger position will explicitly deny Z, on the grounds that it entails a falsehood, namely, Plurality. These philosophers will not only refrain from asserting $(*)$ but actually assert that it is false, on the grounds that the left-hand side is false but the right-hand side is true. In any case, every PM fictionalist will refuse to 
assert (*). Exactly the same goes for other instances of $M F$ where the left-hand side is a non-modal possible-worlds sentence.

Premiss (1) of the argument mentioned in the statement of the Brock-Rosen objection is an instance of $M F$. Since the left-hand side of (1) contains the modal expression 'Necessarily', this side of the biconditional is a modal possible-worlds sentence, unlike the left-hand side of (*). This raises the question: quite generally, how should PM fictionalists treat instances of $M F$ whose left-hand side is a modal possible-worlds sentence?

As I have said, possible-worlds sentences are useful for clarifying our modal claims. But it is not clear that we need to use modal possible-worlds sentences to achieve this end. The purpose of possible-worlds discourse is to provide a way of stating modal claims with greater clarity than ordinary modal talk can provide. Until evidence is provided to the contrary, PM fictionalists may assume that we only need to use non-modal possible-worlds sentences to articulate modal claims. There is no need to adulterate possible-worlds talk with ordinary modal locutions such as 'Necessarily'. It seems that we can resolve the initial dilemma by giving an account of non-modal possible-worlds talk alone.

This means that PM fictionalists have two options for dealing with instances of $M F$ that have modal possible-worlds sentences on the left-hand side. The lazier option is to say nothing about the interpretation of these sentences. That is a perfectly defensible move, since the resolution of the initial dilemma does not require the theorist to say anything about these sentences; as we have seen, it is the non-modal possible-worlds sentences - the ones we need to use to talk clearly about modal matters - whose use stands in need of justification.

The more energetic option is to treat (1) in the same way as Z, by refusing to assert it. Again, there are two ways to go: either refuse to assert the left-hand side, but assert the right-hand side, or, more boldly, deny the left-hand side, assert the right, and thus deny the whole biconditional. There is no need for PM fictionalists to take this more energetic course, but they are free do so do. Whether they choose the lazy or the energetic option, they are not committed to endorsing (1), so the Brock-Rosen objection cannot get off the ground. 
7. Modal fictionalism falters if it merely concerns the interpretation of modal sentences, for no position of this sort can explain why it is legitimate to carry on engaging in possible-worlds discourse without subscribing to Plurality. Both RM fictionalism and PM fictionalism offer to vindicate this practice. No version of modal fictionalism will be tenable, though, unless it can respond to the Brock-Rosen objection. I have argued that RM fictionalists have a simple and natural response available, and I have also argued that PM fictionalism is immune to the objection. It is thus doubly true that the Brock-Rosen objection does not refute modal fictionalism. ${ }^{6}$

\section{Philosophy}

The University of Manchester

School of Social Sciences

Dover Street Building

MANCHESTER

M13 9PL, UK

david.liggins@manchester.ac.uk 


\section{References}

Baldwin, Thomas 1998. Modal fictionalism and the imagination. Analysis 58: 72-5.

Brock, Stuart 1993. Modal fictionalism: a response to Rosen. Mind 102: 147-150.

Brock, Stuart 2002. Fictionalism about fictional characters. Noûs 36: 1-21.

Chihara, Charles 1998. The Worlds of Possibility. Oxford: Clarendon Press.

Divers, John 1999a. A modal fictionalist result. Noûs 33: 317-346.

Divers, John 1999b. A genuine realist theory of advanced modalizing. Mind 108: 217-239.

Divers, John 2002. Possible Worlds. London: Routledge.

Divers, John, and Hagen, Jason 2006. The modal fictionalist predicament. In Identity and Modality, ed. Fraser MacBride. Oxford: Oxford University Press.

Dever, Josh 2003. Modal fictionalism and compositionality. Philosophical Studies 114: 223-251.

Kim, Seahwa 2002. Modal fictionalism generalized and defended. Philosophical Studies 111: 121-146.

Lewis, David 1968. Counterpart theory and quantified modal logic. Journal of Philosophy. 65: 113-126.

Lewis, David 1986. On the Plurality of Worlds. Oxford: Blackwell.

Nolan, Daniel 2002. Modal fictionalism. In Stanford Encycopedia of Philosophy, ed. Edward Zalta. Online at <http://plato.stanford.edu/entries/fictionalism-modal/>.

Nolan, Daniel, and John O'Leary-Hawthorne 1996. Reflexive fictionalisms. Analysis 65: 23-32.

Noonan, Harold 1994. In defence of the letter of fictionalism. Analysis 54: 133-139.

Rosen, Gideon 1990. Modal fictionalism. Mind 99: 327-354.

Rosen, Gideon 1993a. A problem for fictionalism about possible worlds. Analysis 53: 71-81.

Rosen, Gideon 1993b. The refutation of nominalism (?). Philosophical Topics 21: 149-186.

Rosen, Gideon 1995. Modal fictionalism fixed. Analysis 55: 67-73. 
Notes

1. Lewis's is not the only sort of modal realism on the market: other realist approaches identify possible worlds with actually existing entities. I am assuming that these accounts are also problematic. (See Divers 2002 for a survey of the various modal realisms.)

2. In Rosen's original paper, this aspect of modal fictionalism is explained in a different fashion:

[L]et $P$ be an arbitrary modal proposition. The modal realist will have ready a non-modal paraphrase of $P$ in the language of possible worlds; call it $P^{*}$. The realist's assertions about possible worlds are guided by explicit adherence to the schema $P$ iff $P^{*}$. The fictionalist's parasitic proposal is therefore to assert every instance of the schema: $P$ iff according to the hypothesis of the plurality of worlds, $P^{*}$. Like modal realism, the theory would seem to provide truth conditions for modal claims in a systematic way. (Rosen 1990: 333; see also Rosen 1990: 335; Rosen 1993a: 72-73; and Rosen 1995: $67-68)$

But there are two difficulties with formulating the position in this way. (1) It is not clear what is meant by saying that $P^{*}$ is a paraphrase of a proposition: the paraphrase relation relates sentences, not propositions. (2) This formulation needs to be modified to avoid the priority problem mentioned in the text. - When $M F$ is augmented with the stipulation that the right-hand sides of its instances take semantic priority, it avoids both these difficulties.

3. Various other responses to the Brock-Rosen objection have been put forward; for critical discussion, see Nolan 2002 and Divers and Hagen 2006. 
4. It is relevant to note that Noonan's response to Brock-Rosen provides no help with the blue swan objection.

5. A referee has asked me to consider the following objection:

Modal fictionalists must believe that the following argument is sound:

There is not a plurality of worlds.

Possibly, there is not a plurality of worlds. (Standard modal logic)

Possibly, there is not a plurality of worlds iff Acc to PW, there is a world at which there is not a plurality of worlds. (Instance of $M F$ )

Acc to PW, there is a world at which there is not a plurality of worlds. (Modus ponens)

But the conclusion of this argument is false: the hypothesis of the plurality of worlds says that, at every world, there is a plurality of worlds. So the fictionalist is committed to a falsehood.

Relying as it does on $M F$, rather than $M F 2$, this should be classed as a new objection to modal fictionalism: strictly speaking, it is not an objection to RM fictionalism as such or to the response to Brock-Rosen I have advised RM fictionalists to make. All the same, it would be unsatisfying if the adoption of RM fictionalism or of my suggested response to Brock-Rosen were to prevent modal fictionalists from dealing with it. I think this is not the case: the modal fictionalist who adopts RM fictionalism and replies to Brock-Rosen in the way laid out in the text has two ways of responding to the objection. These responses are also open to modal fictionalists more generally.

One way is to refuse to assert the first premiss of the argument. As I have characterised them, fictionalists are philosophers who are unwilling to believe Plurality. I did not burden 
fictionalists with a commitment to denying it: instead, they are free to sit on the fence, neither denying nor asserting that there is a plurality of worlds. Compare Rosen 1993a: 71-2: 'Some philosophers have hoped to earn the right to talk about possible worlds ... without taking on a commitment to the existence of worlds .... Fictionalism is one way to flesh out [this] thought' (my italics).

Some fictionalists, though, will want to assert that there are no such things as worlds; these fictionalists need a different response to the objection. They can do so by noting that modal realists have trouble in adequately translating modal claims about worlds into worlds-talk that is free of modal locutions like 'Necessarily' and 'Possibly'. Following hints in Lewis, Divers (1999b) has suggested that that realists should respond to these problems by translating modal claims about worlds (and certain other modal claims) according to the following schemata:

$P \quad$ Possibly $p$ iff $p$.

$N \quad$ Necessarily $p$ iff $p$.

Modal fictionalists can take another leaf out of the modal realist's book by adopting these ways of translating modal claims about worlds. In other words, they can accept all instances of $P$ and $N$, where $p$ is any possible-worlds sentence - continuing to translate all other modal claims according to $M F$.

This manoeuvre defeats the objection. Since 'There is not a plurality of worlds' is a possible-worlds sentence, this approach prescribes that 'Possibly, there is not a plurality of worlds' should be translated using $P$, not $M F$. So the fictionalist no longer asserts the instance of $M F$ that is the final premiss of the argument mentioned in the objection. Replacing this premiss with the relevant instance of $P$ yields the following argument:

There is not a plurality of worlds.

Possibly, there is not a plurality of worlds. (Standard modal logic) 
Possibly, there is not a plurality of worlds iff there is not a plurality of worlds. (Instance of $P$ )

There is not a plurality of worlds. (Modus ponens)

And patently this presents no threat whatsoever to the fictionalist.

6. My thanks go to Rosanna Keefe, Chris Hookway, John Divers, Dominic Gregory, Daniel Nolan, Rich Woodward, Esa Díaz-León, and Simon Fitzpatrick for discussions of various versions of this paper. Thanks also to audience members at talks at the National Postgraduate Analytic Philosophy Conference, Cambridge (July 2004), the Department of History and Philosophy of Science, University of Athens (October 2004), and the Arché modality conference, St Andrews (June 2006); and to Arif Ahmed, my respondent at the Cambridge conference. I gratefully acknowledge funding from the Arts and Humanities Research Council (in its pre-conciliar phase) and the Analysis Trust. 